\title{
Chronic meningococcemia: a rare presentation of meningococcal disease: case report
}

\author{
Antonio Adolfo Guerra Soares Brandão ${ }^{a}$, Aleksander Snioka Prokopowitsch ${ }^{\mathrm{b}}$, \\ Fernando Peixoto Ferraz de Campos $^{b}$, Liz Andrea Kawabata Yoshiharab
}

Brandão AAGS, Prokopowitsch AS, Campos FPF, Yoshihara LAK. Chronic meningococcemia: a rare presentation of meningococcal disease: case report. Autopsy Case Rep [Internet]. 2012;2(1):29-35. http://dx.doi.org/10.4322/acr.2012.005

\section{ABSTRACT}

Chronic meningococcemia is a rare clinical presentation within the spectrum
of infections due to Neisseria meningitidis, which was first described in 1902 .
It is defined as a chronic and benign meningococcal bacteremia without
meningeal signs or symptoms with at least one week's duration, characterized
by intermittent or continuous fever, polymorphic cutaneous rash, and migratory
arthropathy. The incidence is believed to be around $1: 200,000$ inhabitants. It
affects predominantly young people and adults, and it is equally distributed
between genders. Diagnosis may be challenging in the early stages of the
disease because of the difficulty in isolating Neisseria meningitidis (it reaches
$74 \%$ of positivity in advanced stages). Recently, the use of PCR for detecting
Neisseria sp antigen in skin biopsies specimens has been considered for those
culture-negative cases. The authors report a case of a $54-y e a r-o l d ~ f e m a l e$
patient who sought medical attention for a five-day fever followed by arthralgia
and skin lesions predominantly in the lower limbs. The patient progressed to
a toxemic clinical status that improved after the administration of antibiotic
therapy, which consisted of oxacillin and ceftriaxone. The diagnosis of chronic
meningococcemia was performed after the isolation of Neisseria meningitidis
in two different blood sample cultures. This is, to our knowledge, the first case
of chronic meningococcemia described in Brazil (up to the writing of this report).

Keywords: Meningococcal infections; Arthritis; Immune complex diseases; Purpura; Fever.

\section{CASE REPORT}

A 54-year-old female patient sought medical attention complaining of sore throat and fever for five days. Concomitantly, she experienced painful swelling of both ankles and similar, but less intense, symptoms involving wrist and metacarpophalangeal joints, bilaterally. These complaints revealed progressive worsening. She had a history of hypertension, diabetes mellitus, and dyslipidemia, and was taking captopril, atenolol, glibenclamide, simvastatin, and aspirin. She had a myomectomy 15 years ago and surgical treatment of lumbar herniated intervertebral discs four years ago. The patient was a moderate smoker and used to drink about $40 \mathrm{~g}$ of alcohol per week, but quit both

\footnotetext{
${ }^{a}$ Department of Internal Medicine - Hospital das Clínicas - Faculdade de Medicina - Universidade de São Paulo, São Paulo/SP - Brazil.

${ }^{b}$ Department of Internal Medicine - Hospital Universitário - Universidade de São Paulo - São Paulo/SP - Brazil.

Copyright $\odot 2012$ Autopsy and Case Reports - This is an Open Access article distributed of terms of the Creative Commons Attribution NonCommercial License (http://creativecommons.org/licenses/by/3.0/) which permits unrestricted non-commercial use, distribution, and reproduction in any médium provided article is properly cited.
} 
more than 10 years ago. On initial examination, the patient showed good clinical status, and was ruddy and hydrated. Edema was detected on the lower limbs. Her respiratory rate $=22$ respiratory movements per minute, pulse $=100$ beats per minute, blood pressure $=112 \times 84 \mathrm{mmHg}$, axillary temperature $=36.5{ }^{\circ} \mathrm{C}$. The Glasgow coma scale was 15 , and no nuchal rigidity was found. Physical examination of the lungs and heart was unremarkable, whereas percussion of the abdomen showed dullness over Traube's semilunar space. The joint examination revealed signs of joint effusion in the right knee with limited range of motion and local heat, and swelling and heat in the dorsal region of the left hand. Her skin was free of lesions. Initial laboratory tests are shown in Table 1.

Transthoracic echocardiography showed LVEF $=64 \%$, aorta $=31 \mathrm{~mm}, A E=33 \mathrm{~mm}$, septum $=9 \mathrm{~mm}$, posterior wall $=8 \mathrm{~mm}$, normal right ventricle performance, and absence of vegetation or thrombi, confirmed by transesophageal echocardiogram. Ultrasonography of the abdomen revealed an enlarged liver and the presence of an oval image located in segment III, which was suggestive of hemangioma.

On the first day of hospitalization, besides the persistence of fever, violaceous maculae suggestive of purpura lesions appeared over the swollen and hyperemic lower limbs. Oxacillin had been started since the patient's admission, followed by the association of ceftriaxone. Further laboratory investigation included determinations of serology for HIV, hepatitis B and C, and syphilis, which were negative. Vasculitis associated with rheumatic diseases were ruled out with the negative results for rheumatoid factor, ANF, anti-ds DNA, anti Ro, anti$\mathrm{Sm}$, and normal levels of C3 and C4.

The clinical progression was characterized by the worsening of skin lesions, which became necrotic (Figures 1-2), and arthritis of the left knee and left ankle (Figure 3) ensued. The synovial effusion of the knee was punctured and its analysis showed an inflammatory pattern with negative culture. The gram stain also failed to demonstrate any bacterial presence.

Because of the advanced necrotic stage of the skin lesions, it was decided not to perform a biopsy.

On the fourth day of hospitalization, blood cultures from two different samples showed the growth of Gram negative bacillus further identified as Neisseria meningitides serogroup $\mathrm{C}$.

The patient was prescribed 14 days of Oxacillin and 15 days of ceftriaxone. Despite the antimicrobial regimen, fever persisted in the absence of identifiable infectious focci. Her clinical

Table 1 - Laboratory tests

\begin{tabular}{|c|c|c|c|c|c|}
\hline & $12,4 / 36,3 \%$ & RV & & & RV \\
\hline Hemoglobin & 12.4 & $12.3-15.3 \mathrm{~g} \%$ & BUN & 110 & $5-25 \mathrm{mg} \cdot \mathrm{dL}^{-1}$ \\
\hline Hematocrit & 36 & $36.0-45.0 \%$ & Creatinine & 3.7 & $0.4-1.3 \mathrm{mg} \cdot \mathrm{dL}^{-1}$ \\
\hline Leucocytes & 10100 & $4.4-11.310^{3} / \mathrm{mm}^{3}$ & Potassium & 4.7 & 3.5-5.0 mEq. $\mathrm{L}^{-1}$ \\
\hline Mielocytes & 1 & $0 \%$ & Sodium & 133 & 136-146 mEq. $\mathrm{L}^{-1}$ \\
\hline Metamyelocytes & 4 & $0 \%$ & $\mathrm{ALT}$ & 34 & 9-36 U.L-1 \\
\hline Bands & 8 & $1-5 \%$ & AST & 33 & $10-31$ U. $L^{-1}$ \\
\hline Segmented & 68 & $45-70 \%$ & $\mathrm{AF}$ & 170 & $10-100$ U.L.-1 \\
\hline Eosinophils & 3 & $1-4 \%$ & yGT & 302 & 1-24 U.L-1 \\
\hline Basophils & 0 & $0-2.5 \%$ & Total bilirrubin & 1.96 & $0,3-1,2 \mathrm{mg} \cdot \mathrm{dL}^{-1}$ \\
\hline Linfocytes & 9 & $18-40 \%$ & Direct bilirrubin & 1.52 & $<0,3 \mathrm{mg} \cdot \mathrm{dL}^{-1}$ \\
\hline Monocytes & 7 & $2-9 \%$ & PT (INR) & 1.28 & 1 \\
\hline Platelets & $206 \times 10^{3}$ & $150-40010^{3} / \mathrm{mm}^{3}$ & Albumin & 3,6 & $3-5 \mathrm{~g} \cdot \mathrm{dL}^{-1}$ \\
\hline \multirow[t]{2}{*}{$\mathrm{CRP}$} & 451 & $<5 \mathrm{mg} \cdot \mathrm{L}^{-1}$ & CK & 25 & $26-140$ U. $L^{-1}$ \\
\hline & & & LDH & 203 & $120-246$ U.L-1 \\
\hline
\end{tabular}

$\mathrm{AF}=$ alkaline phosphatase; $\mathrm{ALT}=$ alanine aminotransferase; $\mathrm{AST}=$ aspartate aminotransferase; $\mathrm{BUN}=$ blood urea nitrogen; $\mathrm{CK}=\mathrm{creatine}$ phosphokinase; $\mathrm{CRP}=\mathrm{C}$ reactive protein; $\mathrm{yGT}=$ gamma-glutamyltransferase; INR = international normalized ratio; $\mathrm{LDH}=$ lactate dehydrogenase; $\mathrm{PT}=$ prothrombin time; $\mathrm{RV}=$ reference value. 

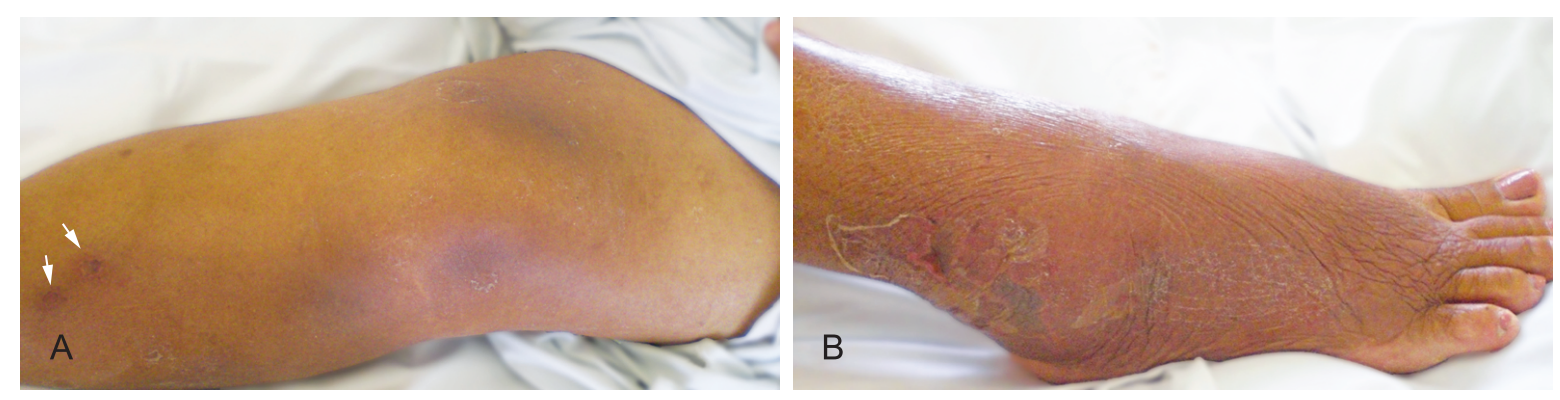

Figure 1 - A - Violaceous maculae suggestive of purpura lesions (arrows) appeared over the swollen and hyperemic lower limbs. Note intense erythema over the knee; B - Necrotic lesions, in the early stage, close to the external malleolus.
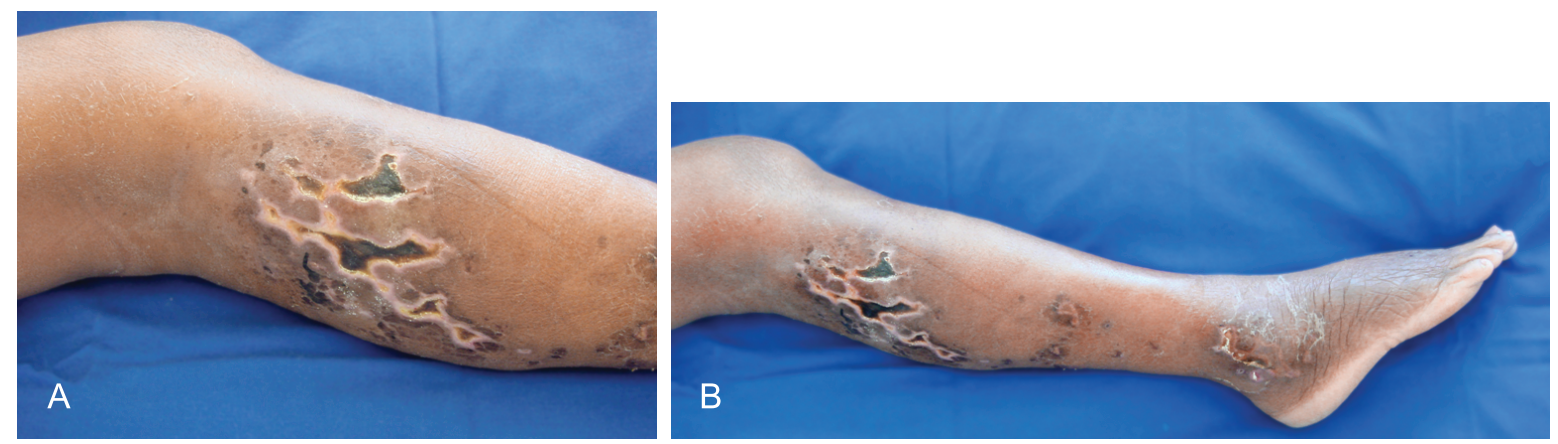

Figure 2 - A - Necrotic lesions over the right calf; B - Note also lesions close to the malleolus and the increased volume of the right knee.
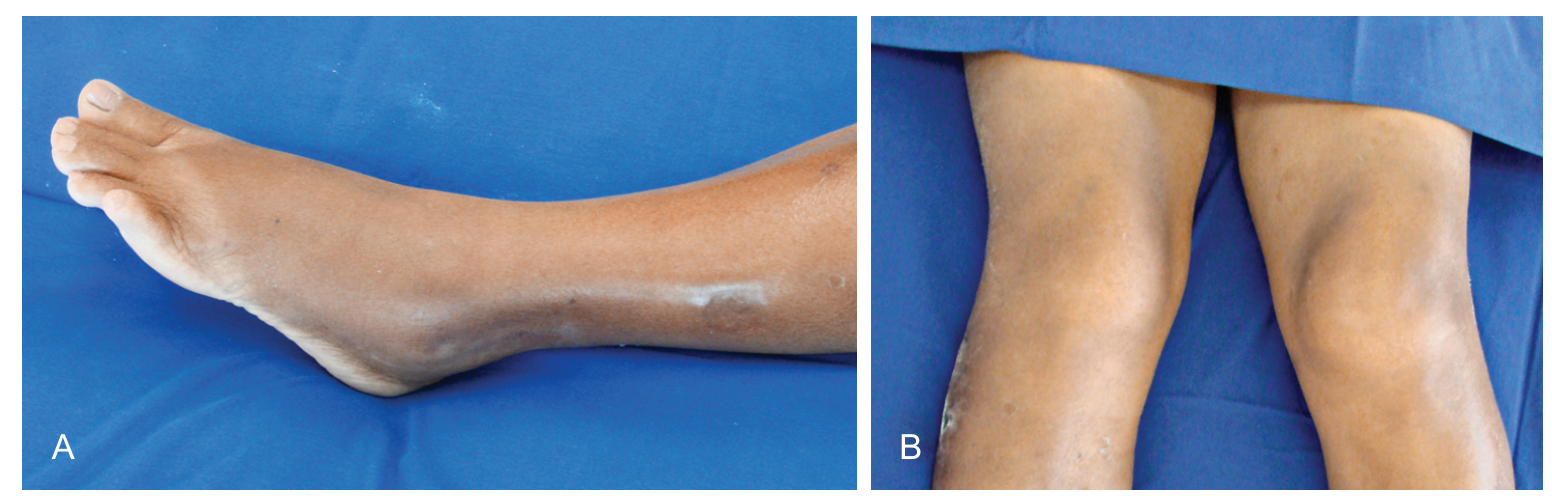

Figure 3- A - Edema of the left ankle; B - Increased left knee volume.

status was favorable allowing corticotherapy with prednisone once the possibility of a post meningococcal reactional status was considered. The patient became afebrile on the eighteenth day of treatment, was discharged with normalization of laboratory tests $(\mathrm{CRP}=15 \mathrm{mg} / \mathrm{dL})$ and healed skin lesions and decreased joint swelling.

\section{DISCUSSION}

Meningococci are diverse organisms and are usually commensal bacteria in humans. According to some studies, $20-40 \%$ of the adult population is permanently or temporarily asymptomatic carriers. ${ }^{1}$ Only a minority of nasopharyngeal isolates cause invasive disease. ${ }^{2}$ Meningococci associated with invasive disease elaborate a capsule, which provides protection from desiccation during transmission and aids in the evasion of host immune mechanisms. The major factor of virulence of these organisms is the release of outer-membrane vesicles that consist of lipooligosaccharide (endotoxin), outer membrane proteins, phospholipids, and capsular polysaccharides, which are used as antigen for vaccine production. ${ }^{2,3}$ 
Chronic meningococcemia is a rare clinical presentation within the spectrum of infections due to Neisseria meningitidis, presenting some particularities regarding the clinical presentation and the evolutive profile. It was first described in 1902 by Salomon. ${ }^{4}$ This infrequent disease is defined as a chronic or benign meningococcal bacteremia without meningeal signs or symptoms with at least one week's duration, characterized by intermittent or continuous fever, polymorphic cutaneous rash, and migratory arthropathy. ${ }^{5,6}$

The incidence and prevalence of chronic meningococcemia are believed to be very low, $1: 200,000 .^{7}$ However, the incidence may be higher as patients are sometimes treated with antibiotics without a previous etiological diagnosis. ${ }^{8,9}$ By the year 2005 there were 200 cases reported in the literature ${ }^{6,10}$, with the largest case series involving four patients. ${ }^{11}$ Searching the scientific databases Scielo and Lilacs by keywords: chronic meningococcemia, meningococcal disease, meningococcal infections, meningococcal infection-epidemiology, meningococcemia, and meningococcic, and in the PubMed data base with the word "chronic meningococcal disease," we found out that this is the first case reported in Brazil until the time of this manuscript submission.

The disease is characterized by affecting predominantly young people and adults (the mean age is of 26.5 years); the distribution between men and women seems to show no difference. ${ }^{5}$ Only about $10 \%$ of reported patients were under 18 years of age. ${ }^{12}$

Fever and chills are presented in all reported cases and series, skin rash was observed in $93.2 \%$, and joint involvement was present in $70.3 \% .{ }^{5}$ Fever can be spiking, persisting, or relapsing. In the series of Benoit et al., the patients who presented intermitent fever had afebrile periods of 2-10 days, while those with continuous fever patterns generally had a septic course..$^{5}$ The patient reported here presented a persistent fever, even after appropriate antibiotic therapy and after a thorough investigation for other infectious foci. Ruling out the possibility of infection, it was assumed that the fever persistence, as well as the cutaneous-articular involvement, was due to a hypersensitivity reaction type III (immune complexes). This immune reaction is more frequently observed in patients with severe meningococcal disease, but it is also observed either in the infection by meningococci serogroup $C$ (the same of this case report) as in adolescents and adults patients. ${ }^{13}$
Skin eruption is the second most frequent clinical sign. ${ }^{5}$ The lesions appear quickly and may present as maculopapular rash $(47.6 \%)$, petechial lesions $(11.9 \%)$, nodular lesions $(13.1 \%)$, or, less frequently, ecchymotic and pustular lesions were noted $^{5,6,14}$ - sometimes even necrotic. ${ }^{15}$ They are painful in $32 \%$ of the cases 10 and involve the trunk, limbs, and extremities, and may affect palms and soles. The evolution may be recurrent. Very different from the lesions of purpura fulminans, they are sterile in most of the cases. The histology shows a polymorphic perivascular infiltrate with erythrocyte extravasation ${ }^{14}$ and deposition of immunoglobulins and C3 in the vessels wall (also different from purpura fulminans where meningococcal septic emboli are found). ${ }^{5,6,10}$ Our patient developed the skin lesions during hospitalization, showing a reticulated pattern suggestive of purpura in some manner similar to the manifestation of purpura fulminans. ${ }^{16}$

The manifestation of joint involvement is usually seen around the first to the twelfth day after the initial symptoms; it is primarily arthralgia with a migratory nature occurring in all joints except the temporo mandibular. Some authors pointed out the great joints, especially the knee, as the most involved joints. ${ }^{17}$ In the series of Benoit et al., arthritis occurred in $31 \%$ and joint effusion was present in 3 of 148 patients of this series. ${ }^{5}$ In the case described herein, there was an exuberant joint involvement with massive joint effusion, which analysis, besides being inflammatory, did not yield the isolation of Neisseria meningitidis, neither on the Gram stain nor in culture media. This finding is consistent with the fact that arthritis in meningococcal disease is usually manifested by immune-mediated mechanisms. Our patient presented arthritis in the left knee and left ankle observed after eight days of the demand for medical service, following a generalized polyarthralgia.

Table 2 summarizes the clinical features reported in the Benoit et al. review, which involved the data of 148 cases of chronic meningococcemia.

The involvement of the meninges is a sign of poor prognosis. ${ }^{5}$ Totan et al. reported a case of a child patient with chronic meningococcemia who presented cholestatic hepatitis, which resolved after the infection treatment. ${ }^{18}$ Op de Coul reported a case of a 14-year-old with a history of fever of four months' duration, rash and arthralgia, with blood sample culture positive to Neisseria meningitidis, suggesting that chronic meningococcemia should be considered in the differential diagnosis of fever of unknown origin. ${ }^{19}$ 
Table 2-Clinical features of chronic meningococcemia 5

\begin{tabular}{cccc}
\hline Symptom & $\begin{array}{c}\text { Occurrence } \\
\text { (\%) }\end{array}$ & Symptom & $\begin{array}{c}\text { Occurrence } \\
(\%)\end{array}$ \\
\hline Fever & 100 & Headache & 61.5 \\
Skin rash & 93.2 & $\begin{array}{c}\text { Previous URT } \\
\text { infection }\end{array}$ & 37.2 \\
$\begin{array}{c}\text { Joint } \\
\text { involvement }\end{array}$ & 70.3 & & \\
\hline
\end{tabular}

URT = upper respiratory tract.

The differential diagnosis of chronic meningococcemia includes disseminated gonococcal infection (DGI) as clinical features are quite similar in both diseases. The diagnosis of DGI is more challenging due to the difficulty of aethiological agent isolation, which is currently possible in about $50 \%$ of the cases. The skin lesions in DGI are typically few, are limited to the extremities, and start as papules, which then progress into hemorrhagic pustules, and the joint involvement is characterized by arthritis and tenosynovitis. ${ }^{20,21}$ Other differential diagnosis possibilities include infective endocarditis, Henoch-Schoenlein purpura, secondary syphilis, connective tissue disorders, drugs eruptions, and systemic vasculitis. ${ }^{6,22}$

Chronic meningococcemia may be selflimiting, but meningitis and death can occur as a late complication. Untreated, the illness may continue for several months and although it may be self-limiting, abrupt change with a fatal outcome is reported. In one series, meningitis occurred as a late complication, and carditis, when present, was responsible for death. ${ }^{6}$ Other complications reported in chronic meningococcemia are pericarditis, nephritis, endocarditis, and epididymitis. Benoit, in summarizing the data of 148 cases of chronic meningococcemia showed that 15 patients died and 59 had secondary complications. ${ }^{5}$

The diagnosis is usually made after isolation of Neisseria meningitidis in blood cultures which show $74 \%$ of positivity, being less frequent in the early stages of the disease. Repeated samplings are frequently required. In the case related herein, it lasted 10 days from the initial symptoms to the positivity of the blood culture. The serotypes isolated in chronic meningococcemia are the same of that in acute meningococcal disease, but the serotype $\mathrm{B}$ represents $60 \%$ of the cases..$^{10}$ Besides, the skin lesions are mainly caused by immune mediated mechanisms and some reports show isolation of Neisseria meningitidis in the culture of the affected skin, ${ }^{23,24}$ as well as the presence of Neisseria antigens by PCR assay in the same material. Skin biopsies should ideally have both a microbiological examination in order to isolate the meningococcus in the skin, and histological examination in order to seek a leukocytoclastic vasculitis, which is found in $78 \%$ of the cases. Recently, the PCR technique specific for Neisseria meningitidis, commonly used on CSF or blood in acute infections, has been implemented conclusively to the diagnosis of chronic meningococcemia in skin biopsies, which encourages the realization of this technique in the case of negative blood cultures..$^{10,25}$

The host-pathogen interaction in chronic meningococcemia may explain the relative benignity of the disease, when compared to other manifestations of meningococcal disease.

Most patients with chronic meningococcemia do not exhibit an immune system disorder; however, there is an association of hypoimmunoglobulinemia, defects in the complement system (mainly related to the components of the membrane attack complexC5, C6, C7, properdin $)^{26,27}$ as well as IgA deficiency ${ }^{28}$, low levels of $\operatorname{lgG}$ and co-infection with HIV. On the other hand, it was observed that complement deficiency did not increase the frequency of chronic meningococcemia. ${ }^{29}$ Even in the absence of massvaccination, a majority of adults, after 25 years of age, are fully immunized against most serotypes of Neisseria meningitidis, leading to very few acute meningococcemia diseases in immunocompetent adults. Thus, the relatively moderate clinical signs of chronic meningococcemia may be explained by a preexistent immunity against Neisseria meningitidis. ${ }^{6}$

With respect to bacteria, a higher prevalence of serogroup B infection is reported. Some authors state that the relatively reduced virulence of serogroup B may partly explain the chronicity of clinical signs and the reduced inflammatory response. An important virulence factor of the meningococcus is the cell-wall component lipopolysaccharide (LPS). The membrane anchoring part of LPS, lipid A, determines how well the meningococcus is recognized by the immune system through a Toll-like receptor 4 (TLR4). ${ }^{30}$ The most active form of LPS contain six fatty acids in the lipid A moiety. Recently, it was described as mutants with penta-acylated lipid A due to a mutation in the IpxL1 gene. ${ }^{31}$ The mutated strains activate TRL4 less efficiently, leading to less cytokine production, which explains the protracted and benign clinical course in patients with $\mathrm{CM}^{32}$ 
Despite the five-days-history, this case fulfilled all the clinical and microbiological criteria for the diagnosis and course of chronic meningococcemia, as described in the literature. This case points to a rare differential diagnosis, whose incidence is decreasing probably due to abusive use of empirical antibiotics nowadays. ${ }^{33}$ Another relevant point is the number of diseases similar to chronic meningococcemia, imposing such a diagnosis in the differential hypothesis among a febrile cutaneous-articular syndrome. ${ }^{6}$

\section{REFERENCES}

1. Yazdankhah SP, Caaugant DA. Neisseria meninitidis: an overview of the carriagestate. J Med Microbiol. 2004;53:821-32. PMid:15314188. http://dx.doi. org/10.1099/jmm.0.45529-0

2. Rosenstein NE, Perkins AB, Stephens DS, Popovic T, Hughes JM. Meningococcal disease. N Engl J Med. 2001;344:1378-88. PMid:11333996. http://dx.doi. org/10.1056/NEJM200105033441807

3. Santos S, Baruque-Ramos J, Tanizaki MM, Lebrun I, Schenkman I PF. Production of outer membrane vesicles (OMV) in batch cultivation of Neisseria meningitidis serogroup B. Braz J Microbiol. 2006;37:488-93.

4. Salomon H. Ueber Meningokokkenseptikaemie. Berl klin Wocheschr. 1902;39:1045.

5. Benoit FL. Chronic meningococcemia: case report and review of the literature. Am J Med. 1963;35:103-12. http:// dx.doi.org/10.1016/0002-9343(63)90167-0

6. Harwood CA, Stevens JC, Orton D, et al. Chronic meningococcaemia: a forgotten meningococcal disease. $\mathrm{Br}$ J Dermatol. 2005;153:664-99. PMid:16120166. http:// dx.doi.org/10.1111/j.1365-2133.2005.06771.x

7. Goldbloom AA, Nickman EH, Seidmon EEP. Meningococcic infections in an Army staging area. Ann Int Med. 1946;24:589. PMid:21025277.

8. Rasmussen LH, Andersen PL. Kroniskmeningokokæmi (chronic meningococcemia). Ugeskrift Laeger 1991;153:3613-4. Danish. PMid:1776205.

9. Hansen L, Christensen JJ, Breu L. Chronic meningococcaemia. Scand J Infect Dis. 2003;35:418-9. PMid:12953960. http://dx.doi.org/10.1080/00365540310011074

10. Roux M, Sire S, Lalnde V, et al. Fiévre prolongée associée à une eruption cutanée diffuse révelant une meningococcemia chronique. Rev Med Interne. 2010;31:4458. French. PMid:20395022. http://dx.doi.org/10.1016/j. revmed.2009.11.010
11. Bloom DS. Chronic meningococcemia: epidemiology, diagnosis and treatment. Calif Med.1965;103:87-90. PMid:14347980. PMCid:1515949.

12. Ploysangan T, Sheth AP. Chronic meningococcemia in childhood: case reportand review of literature. Pediatr Dermatol. 1996;13:483-7. PMid:8987058. http://dx.doi. org/10.1111/j.1525-1470.1996.tb00729.x

13. Goedvolk CA, von Rosenstiel IA, Bos AP. Immune complex associated complications in the subacute phase of meningococcal disease: incidence and literature review. Arch Dis Child. 2003;88:927-30. PMid:14500317. PMCid:1719308. http://dx.doi.org/10.1136/adc.88.10.927

14. Grouteau E, Chaminade S, Karsenty C, Chaix Y, Prere MF, Carriere JP. Meningococcemie chronique: trois cas chez l'enfant immunocompetent. Arch Pediatr. 1998;5:1232-5. French. http://dx.doi.org/10.1016/ S0929-693X(98)81242-6

15. Kernéis $\mathrm{S}$, Mahé $\mathrm{E}$, Heym $\mathrm{B}$, et al. Chronic meningococcemia in a 16-year-old boy: a case report. Cases J. 2009,2:7103. PMid:19829911. PMCid:2740133. http:// dx.doi.org/10.4076/1757-1626-2-7103

16. Lipsker D, Kara F. Retiform purpura. N Engl J Med. 2008;358:e1. PMid:18184954. http://dx.doi.org/10.1056/ NEJMicm073564

17. Bhavnagri S, Steele N, Massasso D, Benn R, Youssef P, Bleasel J. Meningococcal-associated arthritis: infection versus immune-mediated. Intern Med J. 2008;38:71-3. PMid:18190423. http://dx.doi.org/10.1111/j.1445-5994.2007. 01560.x

18. Totan M, Yildiz G, Kalayci AG. An uncommon presentation: chronic meningococcaemia associated with cholestatic hepatitis in a Turkish child. J Trop Pediatr. 2004;50:372-4. PMid:15537727. http://dx.doi.org/10.1093/tropej/50.6.372

19. Op de Coul ME, Kardos G. [An unusual cause of fever: chronic meningococcemia]. Ned Tijdschr Geneeskd. 1996;140:785-7. Dutch. PMid:8668266.

20. Ghosn SH, Kibbi AG. Cutaneous gonococcal infections. Clin Dermatol. 2004;22:476-80. PMid:15596318. http:// dx.doi.org/10.1016/j.clindermatol.2004.07.001

21. Suzaki A, Hayashi K, Kosuge K, Soma M, Hayakawa S. Disseminated gonococcal infection in Japan: a case report and literature review. Intern Med. 2011;50:2039-43. PMid:21921393. http://dx.doi.org/10.2169/internalmedicine. 50.5586

22. Martinez JV, Verbanaz SC, Jordan R, Enriquez N, Efron ED. Meningococcemia cronica. Medicina. 2008;68:298300. Spanish.

23. Shah N, Dadzie OE. Skin culture: another diagnostic tool in chronic meningococcemia. Br J Dermatol. 2010;163:2189. PMid:20331447. 
24. Texereau M, Roblot P, Dumars A, et al. The usefulness of skin culture in the diagnosis of chronic meningoccaemia. J Intern Med. 1997;242:519-20. http://dx.doi. org/10.1111/j.1365-2796.1997.tb00026.x

25. Parmentier L, Garzoni C, Antille C, Kaiser L, Ninet B, Borradori L. Value of a novel neisseria meningitidis: specificpolymerase chain reaction assay in skin biopsyspecimens as a diagnostic toolin chronic meningococcemia. Arch Dermatol. 2008;144:770-3. PMid:18559767. http://dx.doi.org/10.1001/archderm.144.6.770

26. Nielsen HE, Koch C, Mansa B, Magnussen P, Bergmann OJ. Complement and immunoglobulin studies in 15 cases of chronic meningococcemia: properdin deficiency and hypoimmunoglobulinemia. Scand J Infect Dis. 1990;22:31-6. PMid:2320962. http://dx.doi. org/10.3109/00365549009023116

27. Solé D, Leser PG, Arita FN, Naspitz CK. Deficiência do sistema complemento: apresentação de um caso. Rev Bras Alerg Imunol.1990;13:55-7. Portuguese.

28. Theulin A, Rondeau M, Kuhnert C, Boileau J, Weber JC. Chronic meningococcemia and immunoglobulin A deficiency. J Med Microbiol. 2010;59:1375-8. PMid:20651040. http://dx.doi.org/10.1099/jmm.0.021980-0
29. Figueroa JE, Densen P. Infectious diseases associated with complement deficiencies. Clin Microbiol Rev. 1991;4:359e95.

30. Beutler B, Rietschel ET. Innate immune sensing and its roots: the story of endotoxin. Nat Rev Immunol. 2003;3:169e76.

31. Fransen F, Heckenberg SG, Hamstra HJ, et al. Naturally occurring lipid $A$ mutants in Neisseria meningitidis from patients with invasive meningococcal disease are associated with reduced coagulopathy. PLoS Pathog. 2009;5:e1000396. PMid:19390612. PMCid:2667671. http://dx.doi.org/10.1371/journal.ppat.1000396

32. Brouwer MC, Spanjaaard L, Prins JM, van der Ley P, van de Beek D, van der Ende A. Association of chronic meningococcemia with infection by meningococci with underacylated lipopolysaccharide. J Infect. 2011;62:479-83. PMid:21459106. http://dx.doi.org/10.1016/j.jinf.2011.03.010

33. Schaad UB. Arthritis in disease due to Neisseria meningitidis. Rev Infect Dis. 1980;2:880-7. http://dx.doi. org/10.1093/clinids/2.6.880

\section{Conflict of interest: None}

Submitted on: $30^{\text {th }}$ December 2011

Accepted on: $23^{\text {th }}$ January 2012

Correspondence: Divisão de Clínica Médica

Av. Prof. Lineu Prestes, 2565 - Cidade Universitária, São Paulo/SP - Brazil

CEP: 05508-000 - Phone: +55 (11) 3091-9200

E-mail: ffcampos@usp.br 
